\title{
Análise sobre a conscientização ambiental em escolas da rede municipal de ensino
}

Cristina Joziane Brondani (Adm/FEMA $)^{1}$

Marjana Eloísa Henzel (Adm/FEMA)²

\begin{abstract}
RESUMO: Com o intuito verificar como a Educação Ambiental está inserida no planejamento de ensino, realizou-se um estudo do nível de conscientização ambiental de alunos e professores da rede municipal de ensino de um pequeno município do estado do (RS). Verificou-se como a Educação Ambiental está inserida no planejamento de ensino, através da análise de experiências dos professores das Escolas da Rede Municipal de Ensino, da verificação das problemáticas ambientais existentes no município, e da pesquisa por meio de diagnóstico de campo do nível de comprometimento e de conscientização ambiental dos alunos de $4^{a}$ e $5^{a}$ séries do Ensino Fundamental. Analisou-se o contexto escolar observando de que forma os educadores trabalham a problemática ambiental nas Escolas. Avaliou-se nas Escolas as ações educativas voltadas à preservação e valorização do meio ambiente e com base no diagnóstico obtido, sugeriram-se melhorias. Foram verificados e analisados os dados obtidos através das pesquisas e entrevista e, os mesmos foram tabulados para posterior análise e tomada de decisões. Assim, foi possível formular as devidas recomendações para as escolas, as quais deverão implantá-las para poder alicerçar metodologias mais eficazes e diminuir as dificuldades encontradas atualmente.
\end{abstract}

Palavras-chave: meio ambiente; educação ambiental; conscientização.

\section{INTRODUÇÃO}

O estudo aborda a questão ambiental, como forma de acrescer novos valores e fortalecer a consciência ambiental, com a compreensão e colaboração de professores, alunos e comunidade, para que se possa de modo efetivo influir na mudança de atitudes e na percepção do que ocorre a nossa volta, direcionando ações de prevenção ambiental e de melhoria das condições de vida.

Nesse contexto, a escola é considerada o lugar mais adequado para se trabalhar a relação homem-ambiente-sociedade, sendo um espaço propício para a formação de cidadãos críticos e criativos, com uma nova visão de mundo. A preocupação com a preservação do meio ambiente, acentuada nos dias atuais em função das atividades humanas, as quais, sob a ótica de obter recursos necessários para produzir bens e serviços têm gerado a crença de que a natureza existe para servir ao ser humano, ocasionando sérios problemas de degradação ambiental, a ponto de comprometer os recursos naturais, as condições de vida e conseqüentemente, toda a vida futura no planeta.

Segundo Porto (1996, p. 44) a EA surgiu da necessidade de implementação de uma educação voltada para os problemas atuais e urgentes, que preparasse a população para 
viver e se desenvolver em um mundo interdependente e em harmonia com as leis da natureza.

Como qualquer ser vivo, o ser humano retira recursos do meio ambiente para prover sua subsistência e devolve as sobras. Pode-se atribuir o aumento da escala de produção como um importante fator que estimula a exploração dos recursos naturais, elevando substancialmente a quantidade de resíduos.

Aponta-se a Revolução Industrial como um marco importante na intensificação dos problemas ambientais. A parcela de emissões ácidas, de gases de estufa e de substâncias tóxicas, em sua grande maioria é resultante de atividades industriais, associado ao lixo gerado pela população, cada vez mais composto por restos de embalagens e de produtos industrializados. Da mesma forma, o uso indiscriminado de inseticidas, herbicidas, fertilizantes e implementos fizeram com que a agricultura viesse a se tornar uma atividade intensiva de degradação ambiental. O mesmo pode ser dito a respeito da pesca, dos transportes, das atividades comerciais e de serviços.

Por outro lado, as ações para o combate da poluição só iniciaram a partir da Revolução Industrial, embora desde a Antiguidade diversas experiências haviam sido tentadas para remover o lixo urbano que infestava as ruas das cidades prejudicando a saúde de seus habitantes.

A Educação Ambiental surgiu diante da necessidade de se implementar uma educação de caráter interdisciplinar, voltada para os problemas atuais e urgentes, que preparasse a população para viver e desenvolver-se em um mundo interdependente e em harmonia com as leis da natureza, e que abordasse de forma global a busca de soluções.

Segundo Carvalho (2008, p. 51), a EA é concebida inicialmente como preocupação com uma prática de conscientização capaz de chamar a atenção para a finitude e a má distribuição no acesso aos recursos naturais e envolver os cidadãos em ações sociais ambientalmente apropriadas. É em um segundo momento que a EA vai se transformando em uma proposta educativa no sentido forte, isto é, que dialoga com o campo educacional, com suas tradições, teorias e saberes.

O trabalho baseou-se em pesquisas, cujo universo será composto por uma abordagem da consciência real/atual da questão ambiental, bem como na análise da gestão ambiental desenvolvida nas Escolas da Rede Municipal de Ensino.

Esta metodologia evidenciou de forma consistente os principais problemas ambientais do município e o entendimento de alunos e professores com relação às alterações no ambiente, bem como o respectivo índice de consciência ecológica e o modo como as escolas trabalham a EA com os alunos.

Este trabalho apresentou a relação existente entre quem ensina e quem aprende. Como se caracteriza a prática da EA nas escolas, seus reflexos positivos na comunidade e nos processos de degradação ambiental em curso verificados no município.

\section{REFERENCIAL, MATERIAL E MÉTODOS}

O estudo foi desenvolvido em 05 escolas da rede municipal de ensino, de $1^{\mathrm{a}}$ a $5^{\mathrm{a}}$ séries, localizadas no interior do município de Senador Salgado Filho, na Fronteira Noroeste do Estado do Rio Grande do Sul. Conforme dados do Censo Escolar de 2008 são 16 professores e 131 alunos.

A pesquisa enfocou alunos de $4^{\mathrm{a}}$ e $5^{\mathrm{a}}$ séries, em função do grau de entendimento, através da aplicação de questionário aos 30 (trinta) alunos de $4^{\mathrm{a}}$ e $5^{\mathrm{a}}$ séries do Ensino Fundamental da Rede Municipal de Ensino. 
Os 30 (trinta) alunos que responderam afirmaram desenvolver atividades de EA na sua escola.

Segundo Reigota (1998, p. 43) a EA na escola, ou fora dela continuará a ser uma concepção radical de educação, não porque prefere ser a tendência rebelde do pensamento educacional contemporâneo, mas sim porque nossa época e nossa herança histórica e ecológica exigem alternativas radicais, justas e pacíficas.

Conforme Guerra e Gusmão (2000, p. 21), o que torna o trabalho de implementação da EA nas escolas quase que impossível de ser realizado, são professores que acham que já estão velhos demais para mudar os seus métodos de trabalho.

Já de acordo com Delors (2001, p. 288), para poder dar respostas ao conjunto de suas missões, a educação deve organizar-se em torno de quatro aprendizagens fundamentais que, ao longo de toda a vida, serão de algum modo para cada indivíduo, os pilares do conhecimento: aprender a conhecer, isto é, adquirir os instrumentos da compreensão; aprender a fazer, para poder agir sobre o meio envolvente; aprender a viver juntos, a fim de participar e cooperar com os outros em todas as atividades humanas e, finalmente, aprender a ser, via essencial que integra as três precedentes.

Dos mesmos 30 (trinta) alunos, todos afirmaram saber o que é coleta seletiva de lixo. Segundo Dias (2004, p. 287) os altos custos de implantação e manutenção dos sistemas de coleta e tratamento de lixo têm levado ao fracasso muitas tentativas de equacionamento. Como sempre é a comunidade que sofre os maiores impactos ambientais, produzidos pela falta de saneamento dos resíduos domésticos, hospitalares e industriais, com o aumento de doenças.

Conforme Pereira Neto (1989, p. 5), o equacionamento do lixo urbano no nosso país restringe-se apenas à coleta, seguida da destinação a céu aberto "gerando as lixeiras, lixões ou monturos de lixo, que constituem-se no habitat propício de vetores biológicos (moscas, mosquitos, baratas, roedores, etc.) responsáveis pela transmissão de doenças infecciosas, como febre tifóide, salmonelas, amebíase, malária, dengue, cólera, leptospirose, etc., além de contribuir sobremaneira com a poluição do solo, do ar e das águas."

Quanto aos principais causadores da poluição do ar, dos 30 (trinta) alunos questionados, 28 (vinte e oito) afirmaram saber e 02 (dois) declararam desconhecer os causadores. Conforme Dias (2004, p. 306), ocorre que os nossos veículos produzem poluição atmosférica mais do que deviam. Em primeiro lugar porque consomem um combustível de má qualidade, com excesso de enxofre, entre outros fatores que impedem uma combustão mais eficiente, produzindo mais fuligem. Em segundo lugar, porque muitos motores que equipam nossos veículos são de concepção mecânica antiquada, superada e com poucos ou nenhum mecanismo de proteção ambiental, como catalisadores, etc.

Dos mesmos 30 (trinta) alunos questionados, 11 (onze) afirmaram saber o que é efeito estufa e 19 (dezenove) desconhecem seu significado.

Segundo Dias (2004, p 250), a maior parte da contribuição do ser humano para o aumento dos gases na atmosfera ocorre por meio dos processos do metabolismo industrial, mas as alterações na superfície da Terra têm contribuído, de forma significativa. Para tanto (vários dos gases causadores do efeito estufa, implicados nas mudanças climáticas globais, são liberados por esse processo: gás carbônico, desflorestamento e queima de combustível fóssil; metano, das culturas de arroz e da agropecuária; óxido de nitrogênio, queima de biomassa, utilização de fertilizantes, etc.). As mudanças no uso e na cobertura do solo respondem por $70 \%$ das emissões impostas pelas atividades humanas.

Dos 30 (trinta) alunos questionados, 26 (vinte e seis) conhecem os problemas que podem ser causados pelas queimadas e (04) quatro desconhecem.

Conforme Dias (2004, p 247), a área ocupada atualmente por florestas, segundo a $\mathrm{FAO}$, é de apenas $21 \%$. Os objetivos de intervenção nessas áreas variam ao redor do 
mundo, porém a forma que mais se difunde é o desflorestamento para cultivo, associada às queimadas. Outras formas são constituídas por extração de madeira e pastagens.

Dos mesmos 30 (trinta) alunos questionados, 27 (vinte e sete) afirmaram discutir em sua escola questões relacionadas à água e 03 (três) não. Segundo Dias, (2004, p. 318 ) as atividades desenvolvidas nas escolas objetivam estimular discussões em torno do assunto e buscam envolver todos os alunos na preparação de uma lista que contenha as conseqüências da falta de água tratada para a saúde e o conforto da população. Do mesmo modo procura saber se a região de captação da água está devidamente preservada, protegida de atividades humanas que possam comprometer a qualidade da água, bem como solicitar algumas recomendações que possam auxiliar na redução do consumo da água.

Dos 30 (trinta) alunos questionados, 19 (dezenove) afirmaram visitar rios, áreas verdes e a horta escolar com seus colegas, sob a orientação do (a) professor (a) e 11 (onze) não.

Quanto à percepção dos alunos com relação aos problemas ambientais existentes no município, no processo de pesquisa e avaliação, foi também gerado um espaço para a manifestação dos alunos. Nesta avaliação, com pergunta aberta permitindo a liberdade de expressão através da escrita, foram também solicitados quais, na opinião deles seriam os maiores problemas ambientais do município.

Dos 30 (trinta) alunos questionados, nenhum deles afirmou não existirem problemas ambientais no município. 07 (sete) demonstraram não saber da existência de problemas ambientais no município e 23 (vinte e três) afirmaram que existem problemas ambientais e citaram: a) a questão do lixo (o não recolhimento no interior); b) esgoto (lançado diretamente nos rios); c) queimadas; d) poluição dos rios (por lixo); e) desmatamento; f) poluição do ar (uso indiscriminado de agrotóxicos utilizados na agricultura); g) caça de animais ameaçados de extinção.

Segundo Guimarães (1995, p 25), atualmente se sabe que a chave destes problemas apóia-se em boa medida nos fatores sociais, econômicos e culturais que os provocam e que não será possível, por conseguinte, preveni-los ou resolvê-los com meios exclusivamente tecnológicos.

Com relação à conscientização ambiental, grande parte dos alunos acredita, que os problemas ambientais afetam seu dia-a-dia, e que preservando o meio ambiente, sua vida e das gerações futuras será melhor. O gráfico 10 demonstra, que dos 30 (trinta) alunos questionados, 28 (vinte e oito) acham importante preservar o meio ambiente e 02 (dois) não.

Nesse contexto, segundo Reigota (1998, p. 12), a EA aponta para propostas pedagógicas centradas na conscientização, mudança de comportamento, desenvolvimento de competências, capacidade de avaliação e participação dos educandos. Para Pádua e Tabanez (1998, p. 69), a EA propicia o aumento de conhecimentos, mudança de valores e aperfeiçoamento de habilidades, condições básicas para estimular maior integração e harmonia dos indivíduos com o meio ambiente.

Segundo Guimarães (1995, p. 31) é preciso estar claro que conscientizar não é simplesmente transmitir valores "verdes" do educador para o educando; essa é a lógica da educação "tradicional"; é, na verdade, possibilitar ao educando questionar criticamente os valores estabelecidos pela sociedade, assim como os valores do próprio educador que está trabalhando em sua conscientização. É permitir que o educando construa o conhecimento e critique valores com base em sua realidade.

Ao aplicar o questionário aos Professores, os mesmos relataram o modo como a EA é trabalhada nas escolas: metodologia e recursos utilizados, principais temas abordados, 
ações desenvolvidas, bem como suas percepções acerca da conscientização ambiental das crianças.

Quanto à metodologia empregada informaram que trabalham a EA de maneira dialógica através do desenvolvimento de projetos, analisando em conjunto os problemas ambientais e suas conseqüências, articulando com o conteúdo curricular, contextualizando mediante pesquisa de campo, através de observação da realidade local, oferecendo subsídios para a solução de problemas, trabalhos em grupos, debates e através de vídeos. Outras ferramentas utilizadas são palestras de conscientização, produção de textos e paródias, registros e relatórios, troca de experiências/idéias, artes cênicas.

No que diz respeito aos recursos utilizados, os professores citaram utilizar: textos informativos, figuras, documentários, livros, jornais, revistas, desenhos, painéis, cartazes, teatros, recursos audiovisuais, visitas a campo, práticas no jardim e na horta escolar, cantos de sensibilização e reflexão, maquetes, mensagens, sucatas/materiais descartados.

Em se tratando dos principais temas abordados nas aulas de EA, segundo o relato dos professores são discutidos: a vida no Planeta Terra, questões relacionadas aos recursos hídricos, causa/efeitos do aquecimento global, coleta seletiva do lixo, uso de agrotóxicos, cuidado com as plantas, cadeia alimentar, poluição do ar e do solo, saneamento básico, desmatamento, reflorestamento, erosão, camada de ozônio, chuva ácida.

Já a respeito das ações concretas desenvolvidas acerca da EA nas escolas, das 05 (cinco) escolas analisadas, 03 (três) não possuem ações relacionadas à EA e 02 (duas) possuem projetos voltados aos cuidados com a água, coleta seletiva do lixo, reflorestamento e recolhimento de lixo nos arredores da escola.

Em relação à percepção dos professores quanto a capacidade das crianças tornarem-se agentes multiplicadores da conscientização ambiental, as respostas foram as mais diversas possíveis. Os 06 (seis) professores questionados acreditam que as crianças possuem esse perfil.

Dentre as justificativas mencionadas, citam-se:

a) O aprendizado das crianças decorre da observação e realização de atividades em seu cotidiano, tanto escolar, como familiar. Através das ações realizadas na escola, ela estabelecerá relações com o meio em que está inserida, motivando ou até mesmo exigindo mudanças no comportamento dos familiares em relação ao meio ambiente. É mais fácil educar uma criança do que reeducar um adulto permeado por vícios e atitudes cristalizadas através da prática de sua vida;

b) Os alunos levam para a vida o que vivenciam na escola; quando conscientes de que fazem parte do ambiente tornam-se pequenos agentes multiplicadores, iniciando esse processo na sua família, na comunidade e mesmo na escola;

c) A espontaneidade das crianças faz com que elas participem ativamente do desenvolvimento de projetos e atividades propostas. É uma geração que vem sendo conscientizada dos problemas e da finitude dos recursos disponíveis, que, sem sombra de dúvida, buscará soluções para a problemática ambiental;

d) É muito mais fácil uma criança aprender a preservar o meio ambiente do que um adulto mudar seus hábitos. A criança que participar de projetos de preservação ambiental se motiva e cobra mudanças de atitude na sociedade;

e) Os alunos quando se tornarem adultos estarão conscientes do risco que correm e irão tentar utilizar outros meios para não agredir o meio ambiente. Aos poucos vão mostrar a seus pais o mal que podem causar;

f) É através das crianças que os adultos se conscientizam mais e passam a dar maior valor ao meio ambiente. 


\section{RESULTADOS E DISCUSSÕES}

Após o diagnóstico e a análise observa-se que, ao mesmo tempo em que as aulas são dinâmicas e criativas, as dificuldades também caminham nas mesmas proporções. Como em relacionar os conteúdos, a falta de interesse por parte dos alunos, falta de laboratório e de apoio didático e pedagógico. Segundo o levantamento, alguns alunos ainda vêem o assunto como longe da realidade, abstrato, chato.

Percebe-se que para os profissionais é preciso muita criatividade para tornar a aula dinâmica. Dentre as dificuldades pode-se citar a falta de continuidade do trabalho na família, a escassez de recursos materiais, como conscientizar para a prática e como trabalhar interdisciplinarmente.

Nota-se que a inserção do tema ambiental nas escolas se dá com um caráter basicamente informativo, com a utilização de exemplos da atualidade. Mesmo assim percebe-se que a utilização de livros didáticos é ainda incipiente no processo de ensinoaprendizagem.

No contexto das atividades extraclasse / projetos desenvolvidos, a maioria deles se dá por iniciativas de coleta seletiva, monitoramento visual de águas e esgotos, plantios de árvores e visitas esporádicas. Isto é mais um demonstrativo de que a inserção do tema ainda não é suficiente, pois as questões ambientais são muito mais abrangentes e necessitam de tratamento mais aprofundado e específico que o que até agora tem sido trabalhado nas Escolas da Rede Municipal de Ensino do município.

Observa-se que são os professores que mais dão importância instrumentos atrativos, os quais poderão levar os alunos para uma postura cientificamente correta.

A terceira observação que se faz vincula-se à SME. A recomendação é que seja criado um à ministração e aprendizagem dos conceitos relativos às questões ambientais. Entretanto, nota-se também que há uma leve resistência por parte de professores da rede municipal em se trabalhar as questões ambientais de forma ampla.

Durante todo o processo de estudo da pesquisa, tanto bibliográfica como de campo, apresentaram-se quesitos importantes que deviam ser ponderados merecendo a devida atenção para trabalhos futuros, como por exemplo, uma pesquisa com amplitude maior envolvendo não apenas professores e alunos, mas também a população do município.

A primeira observação que se faz relaciona-se a ampliação do currículo escolar, no que diz respeito a busca de profissionais capacitados para atuarem na área aplicando gradualmente conhecimentos e práticas saudáveis para preservar.

A segunda é com relação a infra-estrutura escolar, tendo em vista que a biblioteca é um dos principais instrumentos de pesquisa dos alunos. As escolas, todas localizadas no interior do município, não possuem computadores com acesso a internet, laboratório de ciências e informática e a Biblioteca Pública Municipal localiza-se na sede do município, o que inviabiliza a pesquisa e a torna esporádica.

Deste modo, com o intuito de ofertar uma visão universal dos problemas ambientais e registrar o que ocorre nas proximidades do leitor, deveriam ser colocados à disposição dos usuários, obras versando sobre os problemas e possíveis soluções de danos ambientais globais e locais. Também considera-se importante a instalação de laboratório de ciências e informática nas escolas porque são fatores fortes que complementam e, concretizam o ensino teórico, por serem também, programa de EA, coordenado pela SME, abrangendo as escolas da rede municipal, ensino fundamental. $O$ intuito deste programa seria regrar as ações de EA, por meio de objetivos claros e metodologias específicas. O mesmo pode auxiliar no levantamento dos principais problemas ambientais do município, na sugestão de projetos para as escolas e na organização de ações de culminância (eventos). 
Aquarta observação diz respeito às instituições de ensino superior. A proposta consiste no desenvolvimento de projetos voltados à área ambiental, direcionados a prestação de serviços para empresas, entidades e sociedade em geral. Outro ponto relevante é a introdução da temática ambiental em sala de aula, que se apresenta como uma exigência do atual mercado mundial quanto à necessidade de adaptação das empresas frente à problemática ambiental. Os consumidores cada vez mais, tendem a relacionar a qualidade dos produtos e dos serviços às exigências de um meio ambiente preservado, cabendo portanto, às empresas atualmente apresentar meios para reduzir os impactos que suas atividades causam aos recursos naturais. Daí a importância do desenvolvimento de pesquisas e da elaboração de projetos pelos acadêmicos, que visem melhorias na própria instituição, no que diz respeito ao lixo, ao tratamento dos resíduos, ao consumo de água e energia, podendo ser estendido a comunidade.

A quinta observação associa-se à elaboração de projetos de EA pelas escolas voltados à comunidade. O intuito desta ação é fortalecer os projetos ambientais escolares, através da manifestação e organização de alunos e professores sobre os desafios que as questões ambientais propõem, e com isto estimular a criação de ações práticas concretas pela melhoria do meio ambiente, em cada uma das escolas, envolvendo cada comunidade local.

Este tipo de iniciativa viabiliza o conhecimento sobre o meio ambiente partindo do exame da realidade local, com base nas situações vivenciadas no cotidiano, que visem a sensibilização da população para a necessária mudança de postura e de atitudes frente à problemática ambiental.

\section{CONSIDERAÇÕES FINAIS}

Sendo concluído o processo de análise do universo da pesquisa, verificou-se se buscou responder ao objetivo geral, isto é, analisar como a EA está inserida no planejamento de ensino das Escolas da Rede Municipal de Ensino. Considerou-se importante para o término desta análise que não deve-se demonstrar conformidade mas, repensar paradigmas, não melhorar somente o que já existe mas, inovar, criar, refletir, pensar em novas soluções que levem à ações mais concretas.

Reconhecem professores e alunos que a EA implica em um leque de conhecimentos direcionados principalmente a terra, ar, solo, água, poluição, etc., mas que não se resumam apenas à transmissão de conhecimentos sobre a natureza, mas sim ao desenvolvimento do senso crítico, não no sentido de haver uma disciplina específica para a EA, mas entrelaçada em todas as demais disciplinas. Reconhecem também a necessidade de avaliar as problemáticas ambientais existentes no município, provocadas pela ação humana.

No que tange a forma como os educadores trabalham a problemática ambiental nas Escolas da Rede Municipal de Ensino, pode-se dizer que a EA está longe de ser uma atividade tranquilamente aceita e desenvolvida, porque ela implica mudanças profundas e nada simples. Ao contrário, quando bem realizada, a EA leva a mudanças de comportamento pessoal e a atitudes e valores de cidadania que podem ter fortes conseqüências sociais.

Em se tratando do nível de comprometimento e de conscientização ambiental de alunos e professores, a pesquisa desenvolvida retrata a firme preocupação em favor da questão enfocada. Espera-se, portanto, que esta pesquisa possa acentuar positivamente, nos cuidados com o meio ambiente, bem como na construção de novos conhecimentos e na promoção de transformações no comportamento dos alunos, que culmine na mudança de atitudes com relação à conservação e a preservação ambiental.

No que diz respeito às ações educativas voltadas à preservação e valorização do meio ambiente, percebe-se que as atividades vivenciadas na escola, mesmo que 
superficiais, tornaram os alunos e a própria escola cenário da EA, com o objetivo de recuperar o ambiente, torná-lo agente de desenvolvimento e estrutura de condições e recursos. Vale ressaltar a importância da compreensão dos conteúdos e a participação dos alunos nas atividades pedagógicas, que traduzem-se no envolvimento dos alunos em discussões a respeito de problemas ambientais detectados e, acima de tudo, na vivência de ações, com vistas à solução dos mesmos problemas.

Espera-se, portanto, que esta pesquisa possa contribuir e acentuar positivamente na formação de cidadãos conscientes, de valores positivos, capazes de coexistir em harmonia com o meio ambiente, podendo este estudo ser aprofundado por outros acadêmicos.

\section{REFERÊNCIAS}

CARVALHO, Isabel Cristina de Moura. Educação Ambiental: a formação do sujeito ecológico. 3. ed. São Paulo: Cortez, 2008.

DELORS, J. Educação: um tesouro a descobrir. Relatório UNESCO da Comissão Internacional sobre Educação para o século XXI. São Paulo: Cortez, 2001.

DIAS, Genebaldo F. Educação Ambiental: princípios e práticas. 9. ed. São Paulo: Gaia, 2004.

GUERRA, R.T.; GUSMÃO C.R.C. Implantação de EA em escolas públicas do ensino fundamental: teoria vs. prática. São Paulo: Novos Tempos: 2000.

GUIMARÃES, Mauro. A dimensão Ambiental na Educação. 8. ed. São Paulo: Papirus, 1995.

PÁDUA, S.; TABANEZ, M. Educação Ambiental: caminhos trilhados no Brasil. São Paulo: Ipê, 1998

PEREIRA-NETO, J. T. Compostagem: a Grande Solução ao Equacionamento do Lixo Doméstico. São Paulo: Gaia, 1989.

PORTO, Maria de Fátima M.M. Educação Ambiental: conceitos básicos e instrumentos de ação (Manual de Saneamento e Proteção Ambiental para os Municípios). Belo Horizonte: Fundação Estadual do Meio Ambiente, DESA/UFMG, 1996.

REIGOTA, M. Educação, meio ambiente e cidadania: reflexões e experiências. São Paulo: SMA, 1998.

1 Administradora. E-mail: tinabrondani@yahoo.com.br

2 Prof.Ms. e Tutora: marjaadm@yahoo.com.br 